\title{
Revista Brasisileira Multidisciplinar

\section{Diversidade de Vespas sociais (Hymenoptera, Vespidae) em um Plantio de EUCAlipto no município de BARREIRAS, BAHIA}

Eldair Santos da Silva*; Greice Ayra Franco-Assis*.

${ }^{*}$ Universidade do Estado da Bahia, Campus IX.

*Autor para correspondência e-mail: eldsantos.2013@gmail.com

Palavras-chave

Cerrado

Eucaliptocultura

Vespifauna

\section{KEYWORDS}

Cerrado Eucalyptus Culture

Wasp Fauna
RESUMO: As vespas sociais são insetos de importância ecológica, sendo essenciais no controle biológico em diversos sistemas agrícolas. O objetivo do estudo foi amostrar e analisar a diversidade e abundância da vespifauna em dois talhões de eucalipto, bem como a eficácia dos métodos de captura, no município de Barreiras-BA, durante julho de 2017 a agosto de 2018. As coletas ocorreram mensalmente, por meio de duas metodologias: busca ativa e armadilhas atrativas. Para a análise dos dados, aplicou-se os índices de Shannon-Wiener, Berger-Parker, Constância e Eficiência. Foram coletados 26 indivíduos no TA, e 102 no TB, totalizando 128 vespas, pertencentes a sete gêneros (Agelaia, Brachygastra, Clypearia, Metapolybia, Mischocyttarus, Polistes e Polybia). Polybia foi o gênero mais abundante em ambos talhões, seguido por Metapolybia, Agelaia e Brachygastra. O TA apresentou uma baixa abundância e uma grande diversidade de vespas sociais, já o TB foi mais abundante e menos biodiverso do que o TA. A busca ativa foi o método mais eficaz, seguido pelo método atrativo com maracujá, sardinha e goiaba. Assim, os resultados observados sugerem a necessidade do consórcio de duas ou mais metodologias para mensurar a diversidade e abundância de vespas sociais para que espécies crípticas também possam ser contempladas.

\section{DIVERSITY OF SOCIAL WASPS (HYMENOPTERA, VESPIDAE) IN A EUCALYPTUS PLANTATION IN} THE MUNICIPALITY OF BARREIRAS, BAHIA

Social wasps are insects of ecological importance, being essential for biological control in several agricultural systems. The aim of the study was to sample and analyze the diversity and abundance of wasp fauna in two plots of eucalyptus (TA and TB), as well as the effectiveness of capture methods, in the municipality of Barreiras-BA, from July 2017 to August 2018. The collections took place monthly, using two methodologies, active search and attractive traps. For data analysis, Shannon-Wiener, BergerParker, Constancy and Efficiency indexes were applied. A total of 26 individuals were collected in TA, and 102 in TB, summing up 128 wasps, belonging to seven genera (Agelaia, Brachygastra, Clypearia, Metapolybia, Mischocyttarus, Polistes and Polybia). Polybia was the most abundant genus in both plots, followed by Metapolybia, Agelaia and Brachygastra. TA showed a low abundance and a great diversity of social wasps, whereas TB was more abundant and less biodiverse than TA. The active search was the most effective method, followed by the attractive method with passion fruit, sardines and guava. Thus, the observed results suggest the need for an association of two or more methodologies to measure the diversity and abundance of social wasps so that cryptic species are also covered. 


\section{INTRODUÇÃo}

As vespas são exemplos de insetos com relevante papel ecológico, atuando como polinizadores, predadores de insetos-praga e indicadores de qualidade ambiental, podendo ser classificadas como solitárias ou sociais (PREZOTO; CORTES; MELO, 2008).

Os vespídeos sociais realizam forrageio em busca de outros insetos, mais comumente lagartas de Lepidoptera para alimentação dos imaturos, e contribuem assim, para o controle biológico de insetos-praga (PREZOTO, 1999) em diversos cultivos como cana-de-açúcar, plantio de café, milho e eucalipto. Essas monoculturas são ambientes propícios para o aumento de insetos-praga devido sua característica homogênea.

O cultivo de eucalipto é um exemplo de monocultura, que foi introduzida no Brasil no século XIX, sendo bastante utilizada até os dias atuais, e o seu sucesso é devido ao rápido crescimento e boa adaptação ao clima do país (DOSSA et al., 2002). Entretanto, a baixa heterogeneidade nesses cultivos reduz a quantidade de predadores naturais, acarretando o aumento de pragas, principalmente coleópteros, formigas cortadeiras e lepidópteros desfolhadores, causando prejuízos na produção da cultura.

Muitos estudos sobre a diversidade, abundância e comportamento das vespas sociais têm sido realizados na região sudeste do país. Já na região nordeste e em outras regiões do Brasil, trabalhos sobre diversidade de insetos são mais escassos (ANDENA; CARPENTER, 2014; NEVES et al., 2012). Na região oeste da Bahia, há uma carência de pesquisas com essa temática. O último estudo sobre diversidade de vespas sociais realizado na região, foi por Santos et al. (2009), nos municípios de Barreiras, São Desidério e Riachão das Neves. Porém, não consta na literatura estudos específicos em silvicultura para oeste da Bahia. Esta localidade é considerada um grande polo agrícola e devido à frequente supressão da área nativa do bioma Cerrado, se faz necessário conhecer a diversidade de vespas e o papel que as mesmas desempenham em monoculturas, para possível controle biológico. Vale ressaltar que o manejo de ninhos de algumas espécies de vespas sociais para abrigos artificiais é de grande relevância, possibilitando uma harmonia nesses ambientes homogêneos (ELISEI et al., 2012).

\section{ОвJETIVos}

O objetivo da presente pesquisa foi amostrar e analisar a diversidade e abundância da vespifauna em dois talhões de eucalipto (Eucalyptus urograndis) com diferenças em suas matrizes de entorno, assim como a eficácia dos métodos de captura, no município de Barreiras-BA.

\section{MATERIAl E MÉTODOS}

O experimento foi instalado na Fazenda Planalto ( $12^{\circ} 04^{\prime} 57.4^{\prime \prime}$ S 450 00' 02.3” W), com base em coordenadas geográficas, localizada às margens da BR 242/020 a uma distância de aproximadamente 46 km do centro de Barreiras-BA (1209’ 10” S 44 59’ 24” W) (Figura 1).

O município de Barreiras apresenta duas estações bem definidas, uma chuvosa no verão (entre dezembro e março) e uma seca nos demais meses do ano (SANTOS et al., 2009). Segundo a classificação de Köppen, o clima da região é caracterizado como tropical quente e úmido, com o inverno frio e seco.

Para a condução da pesquisa, foi considerado um mosaico de plantio de eucalipto com cerca de 228 hectares, dividido em quatro talhões, sendo o estudo realizado apenas em dois, denominados de TA e TB. O TA apresenta uma área de 52,7 hectares, fica às margens da rodovia e possui um plantio de soja ao leste. Já TB, com aproximadamente 72,1 hectares, está situado ao lado de uma granja de aves, e apresenta ao norte, uma reserva legal de Cerrado, com cerca de 1258 hectares (Figura 1). Os talhões são compostos por clones de Eucalyptus urograndis (Eucalyptus urophylla X Eucalyptus grandis), plantados no ano de 2010.

Optou-se por esses talhões devido à influência de seu entorno (rodovia e reserva de Cerrado), buscando constatar qual apresenta maior riqueza e abundância de gêneros de vespas. Em cada talhão foi delimitado um transecto de $150 \mathrm{~m}$ x 50m, com borda de 10 metros. 
As vespas foram coletadas mensalmente durante o período de julho de 2017 a agosto de 2018, totalizando 14 coletas. Para a captura destes himenópteros, foram aplicadas duas metodologias, sendo busca ativa e armadilha atrativa.

Figura 1- Mapa da área de pesquisa, Fazenda Planalto, Barreiras-BA.

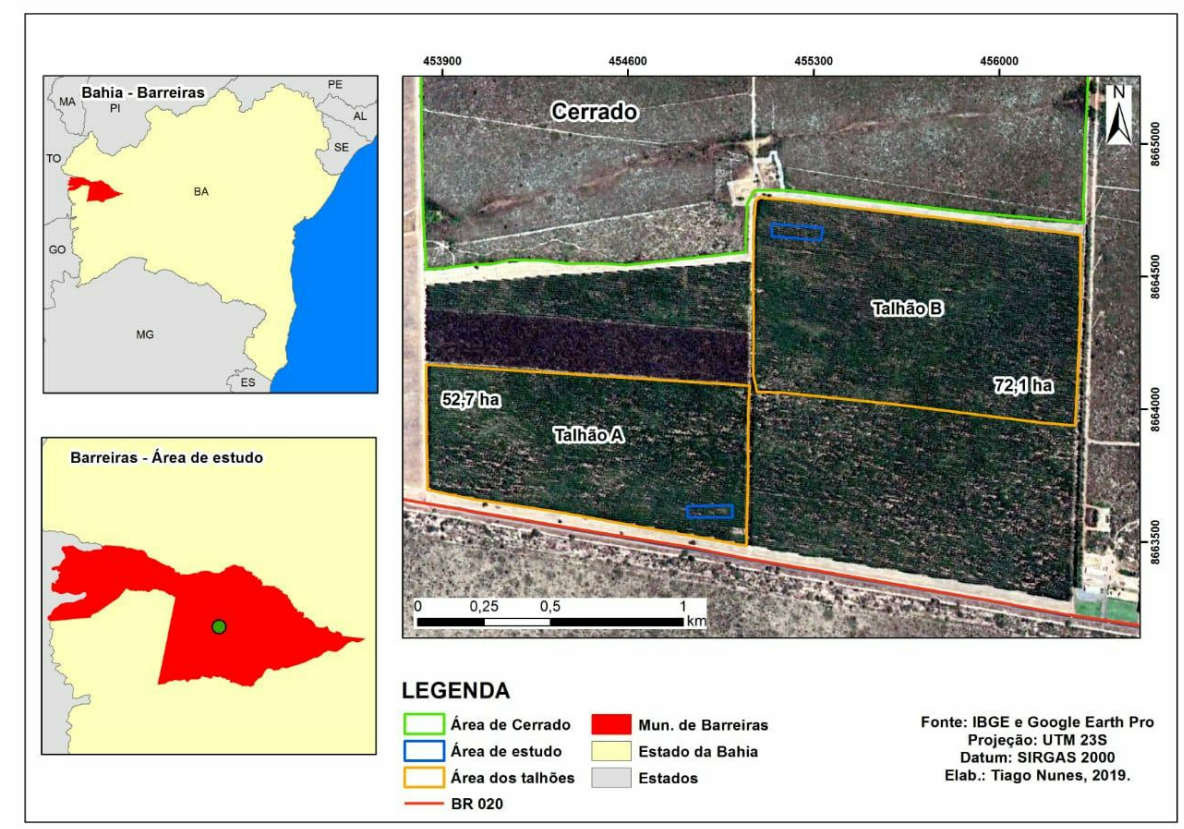

Fonte: Elaborado pelos autores.

A busca ativa foi realizada com redes entomológicas, sendo sempre dois coletores em campo. Para isso, foi necessário inspecionar as folhas, flores e troncos, ao longo dos transectos $(150 \mathrm{~m} \mathrm{x} 50 \mathrm{~m})$, sendo percorrido de três a quatro vezes em cada coleta, aproximadamente. A investigação ocorreu tanto nos dias da instalação das armadilhas atrativas quanto no dia das retiradas das mesmas. O período das buscas para ambos os talhões ficou entre o horário das $08 \mathrm{~h}$ às $17 \mathrm{~h}$, que corresponde à atividade de forrageio das vespas sociais. Os insetos foram acondicionados em câmara mortífera e em seguida, alocados em frascos de vidros de $7 \mathrm{ml}$, contendo álcool 70\%.

Para a aplicação das armadilhas atrativas, utilizou-se o modelo de Ribeiro Júnior (2008) e Barbosa et al. (2018). Foi necessário o uso de garrafas pets de 2 litros, com três aberturas triangulares $(2 \times 2 \times 2 \mathrm{~cm})$ e aproximadamente $10 \mathrm{~cm}$ próximo da base. Nesses recipientes, haviam $150 \mathrm{ml}$ do substrato atrativo de maracujá, goiaba e caldo de sardinha.

Na composição dos substratos atrativos, foi adicionado $1 \mathrm{~kg}$ de polpa da fruta e $200 \mathrm{~g}$ de açúcar, misturados a 1,5L de água. Quanto ao caldo da sardinha, foi acrescentado 1,5L de água para cada sardinha utilizada.

Um total de 10 armadilhas foram distribuídas para cada substrato (maracujá, goiaba e sardinha), somando 30 iscas atrativas, divididas igualmente nos transectos delineados nos talhões A e B. Em seguida, foram presas aos troncos, com barbante, a uma altura de aproximadamente 1,5 metro do solo. Em cada um dos transectos foram distribuídas 15 armadilhas de forma aleatória (determinada por sorteio), com distância de 10 metros entre elas, onde permaneciam no campo por cinco dias (modificado de RIBEIRO JÚNIOR, 2008).

As vespas capturadas por este método também foram acondicionadas em frascos de vidro contendo álcool 70\% e armazenados no Laboratório de Zoologia e Entomologia (LaZooEn) da Universidade do 
Estado da Bahia-UNEB, Campus IX. Cada vespa foi identificada a nível de família e gênero, com o auxílio de um estereomicroscópio e chave dicotômica de Carpenter e Marques (2001).

A diversidade de vespas sociais foi calculada utilizando-se o índice de Shannon-Wiener (H') (SHANNON; WEAVER, 1949). Para o índice de constância, utilizou-se a fórmula C = P x 100/N. A obtenção do índice de frequência foi baseada na classificação de Bodenheimer (1955) apud Silveira Netto et al. (1976), que classifica a presença dos gêneros nas coletas como: gênero constante ( $>50 \%$ nas coletas), acessório (25 a $50 \%)$ e acidental $(C<25 \%)$. Para calcular o índice de dominância, se fez uso do índice de Berger-Parker $(\mathrm{d}=\mathrm{N} \max / \mathrm{N})$, que demonstra a maior proporção da espécie mais abundante. Já o índice de eficiência das metodologias de captura foi calculado pela fórmula IE = S x 100/ N (GIANNOTTI; PREZOTO; MACHADO, 1995). O gráfico representando a abundância das vespas ao longo dos meses da pesquisa foi realizado através do programa SigmaPlot versão 10.

\section{RESUlTADOS E DISCUSSÃo}

\section{AbUNdÂNCIA de VESPAS SOCIAIS}

Foram coletados 26 indivíduos no TA, e 102 no TB, perfazendo um total de 128 vespas. Estas pertencem a sete gêneros (Agelaia, Brachygastra, Clypearia, Metapolybia, Mischocyttarus, Polistes e Polybia) (Tabela 1), representados por uma subfamília (Polistinae) e três tribos (Epiponini, Mischocyttarini e Polistini).

Tabela 1- Gêneros de vespas sociais coletadas em dois talhões (TA, TB) e valores referentes à abundância, riqueza e Índice de Constância dos indivíduos capturados por tipo de metodologia no período de julho/2017 a agosto/2018, na Fazenda Planalto, Barreiras-BA.

\begin{tabular}{|c|c|c|c|c|c|}
\hline \multirow{2}{*}{ Gênero } & \multirow{2}{*}{ Busca Ativa } & \multicolumn{3}{|c|}{ Armadilha Atrativa } & \multirow{2}{*}{ Constância } \\
\hline & & Goiaba & Sardinha & Maracujá & \\
\hline \multicolumn{6}{|c|}{ Talhão A } \\
\hline Agelaia & $2(7,91 \%)$ & 0 & 0 & 0 & \\
\hline Brachygastra & $1(3,84 \%)$ & 0 & 0 & 0 & \\
\hline Clypearia & $1(3,84 \%)$ & 0 & 0 & 0 & \\
\hline Metapolybia & $2(7,91 \%)$ & 0 & $1(3,84 \%)$ & $2(7,69 \%)$ & \\
\hline Mischocyttarus & $1(3,84 \%)$ & 0 & 0 & 0 & \\
\hline Polistes & $1(3,84 \%)$ & 0 & 0 & 0 & \\
\hline Polybia & $4(15,38 \%)$ & $2(7,69 \%)$ & $4(15,38 \%)$ & $5(19,22 \%)$ & \\
\hline Total & $12(46,15 \%)$ & $2(7,69 \%)$ & $5(19,23 \%)$ & $7(26,92 \%)$ & - \\
\hline \multicolumn{6}{|c|}{ Talhão B } \\
\hline Agelaia & $1(0,98 \%)$ & 0 & 0 & 0 & 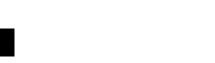 \\
\hline Brachygastra & $2(1,96 \%)$ & 0 & 0 & $1(0,98 \%)$ & \\
\hline Clypearia & 0 & 0 & 0 & 0 & 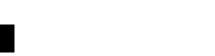 \\
\hline Metapolybia & $3(2,94 \%)$ & $4(3,92 \%)$ & $2(1,96 \%)$ & $5(4,90 \%)$ & \\
\hline Mischocyttarus & 0 & 0 & 0 & 0 & 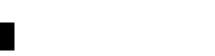 \\
\hline Polistes & $1(0,98 \%)$ & 0 & 0 & $1(0,98 \%)$ & 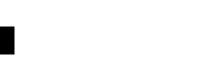 \\
\hline Polybia & $38(37,24 \%)$ & $7(6,86 \%)$ & $20(19,60 \%)$ & $17(16,66 \%)$ & 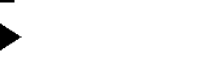 \\
\hline Total & $45(44,11 \%)$ & $11(10,78 \%)$ & $22(21,56 \%)$ & $24(23,52 \%)$ & \\
\hline
\end{tabular}

$=$ Constante $(\mathrm{C}>50 \%) ; \boldsymbol{\underline { }}=$ Acessórios $(25 \%<\mathrm{C}<50 \%) ; \boldsymbol{\square}=$ Acidental $(\mathrm{C}<25 \%)$.

Fonte: Elaborado pelos autores. 
No TA, a abundância de vespas sociais foi superior logo nos meses iniciais do estudo (julho e agosto de 2017) (Figura 2). Já nos meses de novembro e dezembro do mesmo ano, não se obteve registro. Nas etapas seguintes, houve um aumento na captura das vespas, sendo o mês de fevereiro, o período mais abundante e com maior índice de precipitação (Figura 2). Esse resultado concorda com os obtidos por Barbosa et al. (2018) e Detoni et al. (2018), que também encontraram maior abundância de vespas no período quente e úmido. Tais autores justificam o maior número de vespas nesse período em decorrência de temperaturas mais elevadas, assim como a disponibilidade de recursos (HENRIQUES; DINIZ; KITAYAMAB, 1992) no ambiente, o que favorece uma maior atividade de forrageio das vespas sociais. No presente estudo, a abundância e a diversidade das vespas sociais não foram relacionadas com a fenologia dos eucaliptos.

Figura 2 - Número de vespas sociais coletadas nos talhões A (TA) e B (TB) e o registro pluviométrico (mm) no período de julho/2017 a agosto/2018, na Fazenda Planalto, Barreiras-BA.

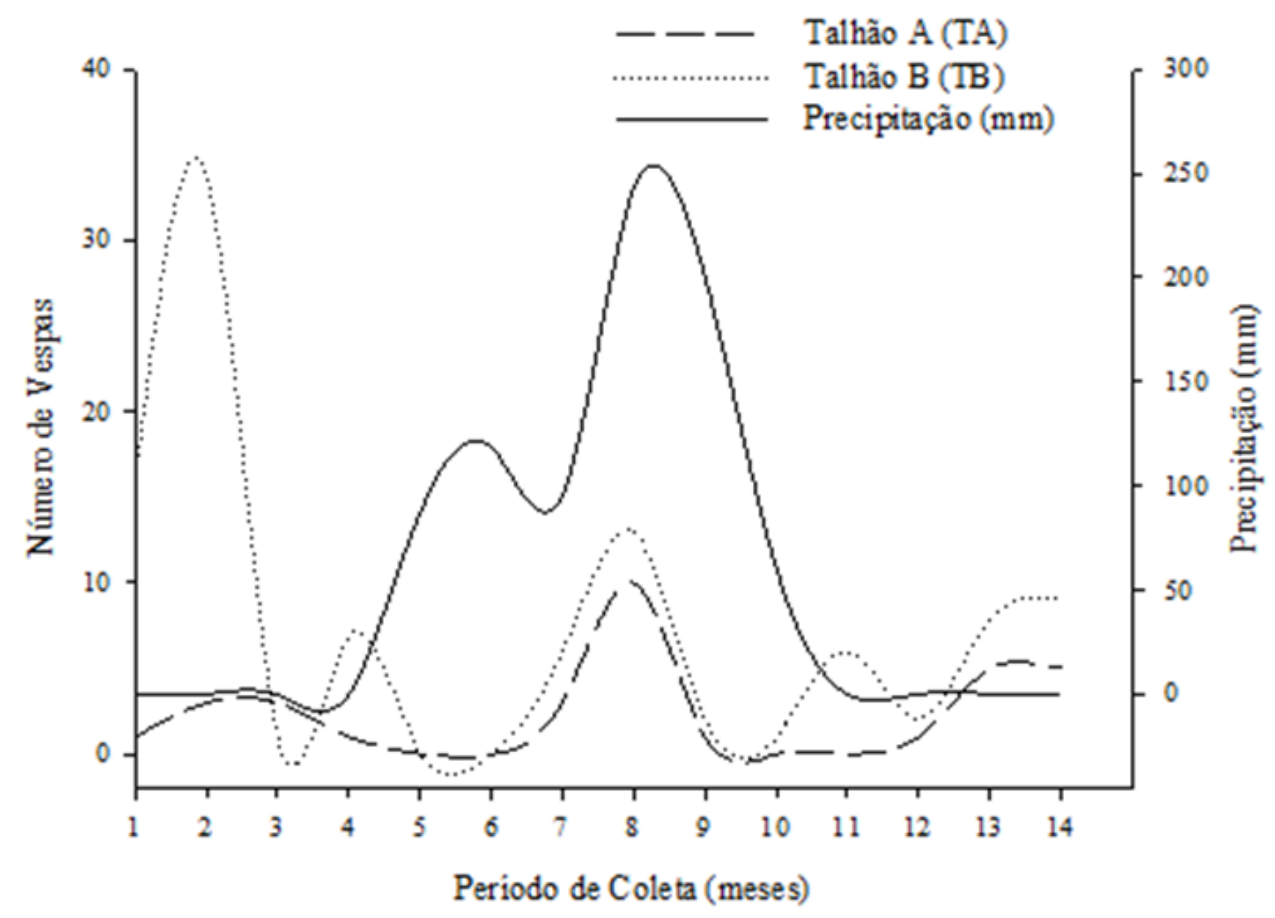

Fonte: Elaborado pelos autores.

O gênero mais abundante no TA, foi Polybia, seguido por Metapolybia e Agelaia (Tabela 1). Muitos estudos já constataram o gênero Polybia como um dos mais abundantes, devido a sua fundação por enxameamento, possuindo milhares de indivíduos em uma colônia (BARBOSA; MACIEL; PREZOTO, 2016b; SOUZA; VALE; BARBOSA, 2016; SOMAVILLA; OLIVEIRA; RAFAEL, 2017) e sendo um dos gêneros mais constantes na América do Sul (BARBOSA et al., 2016a). Outro fator que pode justificar a presença desse gênero, é que algumas espécies de vespas podem realizar forrageio a cerca de 200 metros em torno do próprio ninho (CARPENTER; MARQUES, 2001). Agelaia são vespas sociais que geralmente, nidificam em troncos e cupinzeiros (CARPENTER; MARQUES, 2001; SOMAVILLA; OLIVEIRA; SILVEIRA, 2012), entretanto, dentro dos transectos e em seus arredores, não foi observado a presença de árvores mortas ou cupinzeiros, o que provavelmente justifica o baixo registro desse gênero.

Quanto ao TB, os meses com maior abundância foram julho e agosto de 2017, enquanto que, nos meses de novembro e dezembro de 2017, não houve captura de vespas (Figura 2). Tal fato é possível ser 
justificado, devido à grande disponibilidade de alimentos na área de Cerrado, já que os meses de novembro e dezembro correspondem ao período de chuva nessa região (BATISTELLA et al., 2002) (Figura 2) e, consequentemente, a floração nesse bioma. Observa-se, portanto, que os dados da presente pesquisa divergem de Brugger et al. (2019b), levando em consideração que o estudo do autor em questão analisou menor abundância nos meses de julho e agosto.

Também no TB, o gênero Polybia foi o mais abundante, seguido por Metapolybia e Brachygastra (Tabela 1). A abundância das vespas sociais nesse talhão pode estar relacionada com a presença da reserva legal de Cerrado, que se encontra próxima ao mesmo, tanto ao norte, quanto ao leste (Figura 1). Alguns autores relatam a importância de um fragmento de mata nativa, que auxilia na presença de predadores naturais em áreas agrícolas. Devido à grande disponibilidade de alimentos (insetos-praga) nessas culturas, a atividade de forrageio das vespas sociais se intensifica, e tal fator pode justificar a presença desses indivíduos nesses ambientes com uma maior frequência (SANTOS et al., 2009; DALLÓ et al., 2017; DETONI et al., 2018; PREZOTO et al., 2019).

Apesar da divergência com outros estudos quanto ao número de vespas, os meses com maior e menor quantidade de indivíduos (julho/agosto e novembro/dezembro, respectivamente) foram similares em ambos talhões. No Cerrado, a estação chuvosa compreende os meses de outubro a março (MALHEIROS, 2016), e a floração das plantas ocorre com mais intensidade nos meses de novembro a janeiro (PILON, UDULUTSCH; DURIGAN, 2015), o que provavelmente pode ter resultado na queda do número de vespas nos meses de novembro e dezembro.

\section{Diversidade de Vespas Sociais nOS TALHões TA E TB}

O talhão A apresentou uma menor abundância de vespas sociais (Tabela 1). Em contrapartida, sua diversidade $\left(H^{\prime}=1,40\right)$ foi superior ao talhão $B\left(H^{\prime}=0,29\right)$. No TA, foram encontrados sete gêneros de vespas, sendo em sua maioria, coletados por busca ativa (Tabela 1). A riqueza de gêneros no talhão $\mathrm{A}$, por ser mais próximo à rodovia, apresenta um efeito de borda maior de luminosidade e vento. Tais fatores podem ter influenciado no resultado observado, uma vez que a luminosidade é uma possível condição para maior diversidade de vespas na borda de um fragmento (RIBEIRO JÚNIOR, 2008; LIMA, 2008), pois estimula a atividade de forrageio (DETONI; PREZOTO, 2021).

Quanto ao talhão B, a diversidade foi menor $\left(\mathrm{H}^{\prime}=0,29\right)$, coletando-se apenas cinco gêneros, sendo Agelaia, Brachygastra, Metapolybia, Polistes e Polybia (Tabela 1). A baixa diversidade no TB, possivelmente está relacionada à reserva de Cerrado. Pirani, Sanchez e Pedroni (2009), Pilon, Udulutsch e Durigan (2015) e Pereira et al. (2016) realizaram trabalhos com relação à fenologia de plantas do Cerrado, nos quais constataram a floração e frutificação ao longo de todo o ano. Essa observação ressalta a constância na disponibilidade de alimentos nesse bioma, o que pode justificar a menor atividade de forrageio das vespas no plantio. Como citado anteriormente, a luminosidade é outro fator que possivelmente influenciou na diversidade do TB, pois apresenta pouca intensidade de luz.

Quanto ao índice de dominância de Berger-Parker, o TA $(\mathrm{d}=0,58)$ foi inferior ao TB $(\mathrm{d}=0,80)$ devido à baixa abundância de vespas. Esse contraste, quanto à dominância, está relacionado à maior atividade de forrageio, pois, segundo Barbosa, Maciel e Prezoto (2016b) e Brugger et al. (2019a), as vespas pertencentes à tribo Epiponini possuem um grande número de operárias, o que contribui e justifica a captura das mesmas, buscando por recursos alimentares nas proximidades da reserva de Cerrado. Outro resultado semelhante foi o de Freitas et al. (2015), no qual também constataram maior dominância de vespas em plantio de café associado a um fragmento de mata.

ÍNDICE DE CONSTÂNCIA DAS VESPAS SOCIAIS

A maioria dos gêneros identificados foi acidental $(C<25 \%)$, sendo apenas Polybia identificada como 
acessória e constante nos talhões TA e TB, respectivamente (Tabela 1). Autores como Aguiar e Santos (2007), Silva e Silveira (2009), Freitas et al. (2015), Barbosa, Maciel e Prezoto (2016b) e Virgínio, Maciel e Barbosa (2016) expressam informações semelhantes aos dados da presente pesquisa, nos quais o gênero Polybia foi um dos mais expressivos. Contudo, diferem dos dados encontrados por Ribeiro Júnior (2008) em eucaliptocultura, em que Polybia foi classificada somente como acessória e acidental e não como constante. A grande frequência desse gênero, pode ser explicada, segundo Dalló et al. (2017) e Prezoto et al. (2019), por sua ação de forrageio, que ocorre entre 150 a 300 metros no entorno do ninho.

O gênero Metapolybia também foi constante no TB, porém, no TA foi acidental (Tabela 1). Esse resultado pode estar relacionado com a presença da reserva de Cerrado ao Norte e Leste do talhão B, o que possibilita abrigo para as vespas, e pelo plantio favorecer a presença de insetos pragas. Santos et al. (2009) realizaram um estudo de diversidade de vespas sociais, por busca ativa por ninhos, e obtiveram um resultado similar desse gênero em área de sistema agrícola, na região oeste da Bahia. Gomes e Noll (2009) coletaram uma espécie de Metapolybia presente em área próxima a corredores ecológicos, o que pode explicar sua abundância no $\mathrm{TB}$, devido à proximidade da vegetação nativa de Cerrado.

Polistes e Brachygastra foram classificadas como acidentais (Tabela 1). O gênero Polistes apresenta poucas dezenas de indivíduos por colônia, o que resultou em um menor número de capturas. Segundo Barbosa, Maciel e Prezoto (2016b), a baixa frequência deste gênero pode ser explicada devido ao tamanho reduzido de seus ninhos e por apresentar uma população pequena. Melo et al. (2015), em uma área de Caatinga, também verificaram uma espécie do gênero Brachygastra sendo acidental $(<25 \%)$, assim como Barbosa (2015), em área urbana, que identificou as espécies desses gêneros como acidentais $(<25 \%)$, em sua maioria.

Agelaia, Mischocyttarus e Clypearia, devido à sua baixa frequência, são classificadas como acidentais nos talhões A e B (Tabela 1). O gênero Agelaia e Clypearia, apesar de serem enxameantes, apresentam poucos registros, assim como Mischocyttarus e Polistes, que são de colônias independentes. O hábito de nidificação de Agelaia pode ter influenciado nesse resultado, levando em conta que na área estudada não foi encontrado ambientes propícios para a construção de ninho das vespas desse gênero (CARPENTER; MARQUES, 2001; SOMAVILLA; OLIVEIRA; SILVEIRA, 2012). Santos et al. (2009), não registraram nenhum desses gêneros em sistemas agrícolas (áreas onde se removeu a vegetação natural), apenas em campo sujo (Mischocyttarus) e Cerrado arbóreo (Agelaia e Mischocyttarus). No estado da Bahia, ocorre apenas uma espécie do gênero Clypearia (Clypearia angustior) (BARBOSA et al., 2016a). Brugger et al. (2019b) coletaram em um fragmento de Floresta Atlântica, em área urbana, apenas um exemplar de Clypearia e Felippotti et al. (2010), afirmam que as espécies desse gênero são raras, e pouco se sabe sobre a sua biologia.

\section{ÍNDICE DE EFICIÊNCIA DOS MÉTODOS DE COLETA}

Com base nos índices de eficiência de captura das armadilhas, a busca ativa apresentou maior eficácia que a atrativa, pois coletou maior riqueza de vespas sociais tanto no talhão A quanto no B (Figura 3). Em uma revisão sistemática, Barbosa et al. (2016a), Maciel, Barbosa e Prezoto (2016) e Barbosa, Maciel e Prezoto (2020), enfatizam a busca ativa como método mais eficiente de captura, uma vez que possibilita a interceptação do voo e consequentemente, o encontro de espécies menos corriqueiras.

Quanto às armadilhas atrativas, o substrato contendo suco de maracujá foi mais efetivo, seguido por sardinha e goiaba (Figura 3). Ribeiro Júnior (2008) e Souza et al. (2010) também verificaram o substrato de maracujá como mais eficaz, já que coletou uma riqueza maior de vespas. O substrato maracujá concentra uma maior quantidade de açúcar e alta taxa de fermentação, este fato possivelmente contribuiu para a eficácia desse substrato (MACIEL; BARBOSA; PREZOTO, 2016). Características como estímulos visuais e odor liberado pela armadilha atrativa de goiaba estão relacionados à atração das vespas pelo substrato 
(BRUGGER et al., 2019b), que foi a segunda armadilha mais bem sucedida para vespas em eucaliptocultura.

Figura 3- Índice de eficiência de captura da busca ativa e armadilhas atrativas (com substratos de goiaba, sardinha e maracujá) no talhão A (TA) e B (TB), na Fazenda Planalto, Barreiras-BA, no período de julho/2017 a agosto/2018.

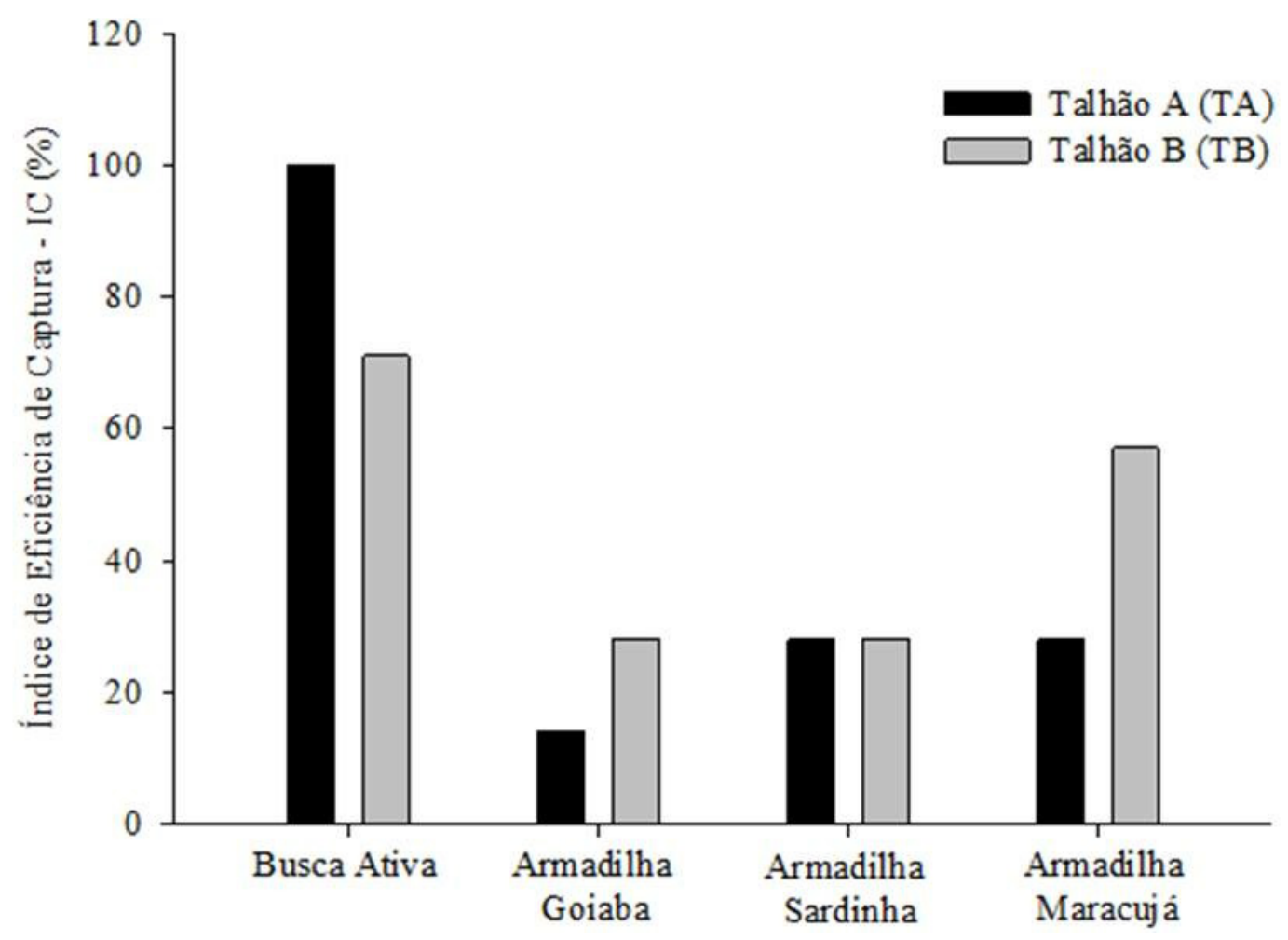

Fonte: Elaborado pelos autores.

\section{ÍNDICE DE DIVERSIDADE E DOMINÂNCIA DA BUSCA ATIVA E DAS ARMADILHAS ATRATIVAS}

Com relação aos métodos de coletas, a busca ativa teve maior diversidade no TA $\left(H^{\prime}=0,73\right)$ do que as armadilhas atrativas. Esse resultado corrobora com Barbosa $(2015)\left(\mathrm{H}^{\prime}=1,2111\right)$, que desenvolveu uma pesquisa em um dossel e sub-bosque em fragmento urbano. Barbosa et al. (2016a) apontam esse método como o mais utilizado em estudos de diversidade e o mais eficaz, pois possibilita a localização de espécies menos abundantes.

Quanto às armadilhas atrativas no TA, o substrato que apresentou uma maior diversidade foi o suco de maracujá $\left(H^{\prime}=0,25\right)$, seguido por sardinha $\left(H^{\prime}=0,21\right)$ e goiaba $\left(H^{\prime}=0\right)$. Em um estudo semelhante, Barbosa et al., (2018) também demonstraram que o substrato de maracujá foi melhor na captura de espécies de vespas. Já Freitas et al. (2015), trabalhando com plantas de café, observaram que o substrato que se destacou foi o suco de goiaba, sendo mais atrativo do que o substrato com suco de maracujá e sardinha. O suco de goiaba só apresentou maior diversidade no plantio de café associado a um fragmento florestal, o que diverge dos dados da pesquisa atual. Contudo, lembra-se que o TA possui maior efeito de borda (luminosidade e vento), podendo assim, ter contribuído para maior diversidade vespas no substrato maracujá. 
Já no TB, a armadilha atrativa com o substrato com suco de maracujá $\left(H^{\prime}=0,35\right)$ apresentou maior diversidade do que a busca ativa $\left(H^{\prime}=0,27\right)$, seguido por goiaba $\left(H^{\prime}=0,27\right)$ e sardinha $\left(H^{\prime}=0,13\right)$. Freitas et al. (2015), em um plantio de café (não associado ao fragmento florestal), também constataram que o substrato com suco de maracujá foi mais eficaz que o suco de goiaba e sardinha. Ribeiro Júnior (2008), averiguou que o substrato contendo suco de goiaba $\left(H^{\prime}=0,29\right)$ teve diversidade mais expressiva do que o substrato de sardinha $\left(H^{\prime}=0,18\right)$. Todavia, a busca ativa obteve uma diversidade maior que $o$ substrato com suco de maracujá. Togni (2009) também obteve maior diversidade na armadilha atrativa e tal resultado pode ser entendido devido à maior permanência das mesmas em campo, resultando em um maior período amostral. A maior riqueza dos substratos atrativos de maracujá e goiaba, comparado ao caldo de sardinha, pode ser explicada pela dieta alimentar das vespas adultas ser rica em carboidrato.

Em relação ao índice de dominância entre as metodologias, o substrato com caldo de sardinha no TA $(\mathrm{d}=0,80)$ e TB $(\mathrm{d}=0,90)$ obteve maior dominância de indivíduos, estando em conformidade com os dados obtidos por Ribeiro Júnior (2008) e Simões, Cuozzo e Frieiro-Costa (2012), que também obtiveram resultado similar. Utilizando caldo de sardinha, registraram um maior número de indivíduos $(\mathrm{d}=0,9905)$, seguido por maracujá $(\mathrm{d}=0,6382)$ e busca ativa $(\mathrm{d}=0,2958)$.

Diante dos dados expostos, se faz necessário intensificar os estudos voltados para diversidade e ecologia das vespas sociais no Cerrado remanescente e em outras plantas cultivadas no oeste da Bahia, visto que as mesmas atuam como agentes de controle biológico.

\section{Conclusão}

As vespas sociais apresentaram maior diversidade no talhão $\mathrm{A}$ e foram abundantes no talhão $\mathrm{B}$. Entre os métodos de captura, a busca ativa obteve maior representatividade, sendo mais eficiente nas coletas dos vespídeos. Diante dos resultados alcançados, observa-se a necessidade do consórcio de duas ou mais metodologias para se mensurar, com maior precisão, a diversidade e abundância de vespas sociais em uma determinada área.

\section{Agradecimentos}

À Universidade do Estado da Bahia Campus IX pelo apoio logístico. Aos professores Dr. Adilson Alves da Costa pela colaboração na análise dos dados obtidos, ao Me. Moisés Pedreira de Souza e à Fazenda Planalto por ceder o espaço para a pesquisa. A todos aqueles que contribuíram com a coleta dos insetos.

\section{REFERÊNCIAS}

AGUIAR, C. M. L.; SANTOS, G. M. M. Compartilhamento de Recursos Florais por Vespas Sociais (Hymenoptera:Vespidae) e Abelhas (Hymenoptera: Apoidea) em uma Área de Caatinga. Neotropical Entomology, v. 36, n. 6, p. 836-842, 2007.

ANDENA, S. R.; CARPENTER, J. M. 2014. Checklist das espécies de Polistinae (Hymenoptera, Vespidae) do semiárido brasileiro. In: Artrópodes do Semiárido: biodiversidade e conservação. Feira de Santana: Printmídia, capítulo 14, p. 169-180.

BARBOSA, B. C.; MACIEL, T. T.; PREZOTO, F. Eficiência de métodos de amostragem de vespas sociais. Brazilian Journal of Development, v. 6, n. 10, p. 83225-83236, 2020.

BARBOSA, B. C.; SILVA, N. J. J.; ZANUNCIO, J. C.; PREZOTO, F. 2018. Occurrence of social wasps (Hymenoptera: Vespidae) in a sugarcane culture. Sociobiology, v. 65, n. 2, p. 320-324, 2018. 
BARBOSA, B. C.; DETONI, M.; MACIEL, T. T.; PREZOTO, F. Studies of social wasp diversity in Brazil: Over 30 years of research, advancements and priorities. Sociobiology, v. 63, n. 3, p. 858-880, 2016 a.

BARBOSA, B. C.; MACIEL, T. T.; PREZOTO, F. Comunidade de vespas sociais (Hymenoptera: Vespidae) do município de Juiz de Fora: riqueza, similaridade e perspectivas. Multiverso: Revista Eletrônica do Campus Juiz de Fora-IF Sudeste MG, v. 1, n. 2, p. 152-160, 2016 b.

BARBOSA, B. C. Vespas Sociais (Vespidae: Polistinae) em Fragmento Urbano: Riqueza, Estratificação e Redes de Interação. 2015. 60 f. Dissertação (Mestrado em Comportamento e Biologia Animal) - Universidade Federal de Juiz de Fora, Juiz de Fora, Minas Gerais, Brasil. 2015.

BATISTELLA, M.; GUIMARÃES, M.; MIRANDA, E. E.; VIEIRA, H. R.; VALLADARES, G. S.; MANGABEIRA, J. A. C.; ASSIS, M. C. Monitoramento da expansão agropecuária na região Oeste da Bahia. Campinas, São Paulo, EMBRAPA: Monitoramento por satélite, 41p. 2002.

BRUGGER, B. P.; CRUZ, R. A. 1.; CARVALHO, A. G. de; SOARES, M. A.; PREZOTO, F.; ZANUNCIO, J. C. Polybia fasticiosuscula (Hymenoptera: Vespidae) Foraging Activity Patterns. Florida Entomologist, v. 102, n. 1, 2019a.

BRUGGER, B. P.; PREZOTO, F.; DE SOUZA, L. S. A.; ZANUNCIO, A. J. V.; SOARES, M. A.; WILCKEN, C. F.; ZANUNCIO, J. C. Use of fruit juice as a method for the collection of social wasps. Florida Entomologist, v. 102, n. 3, p. 592-595, 2019b.

CARPENTER, J. M.; MARQUES, O. M. Contribuição ao estudo dos vespídeos do Brasil (insecta, hymenoptera, vespoidea, vespidae). v. 2, Cruz das Almas, Universidade Federal da Bahia, série Publicações Digitais, 2001, p. 147.

DALLÓ, J. B.; SOUZA, M. M.; COELHO, E. L.; BRUNISMANN, A.G. Vespas sociais (Hymenoptera, Vespidae) em cultura de bucha vegetal Luffa aegyptiaca Mill. Revista Agrogeoambiental, v. 9, n. 4, 2017.

DETONI, M.; PREZOTO, F. 2021. The Foraging Behaviour of Neotropical Social Wasps. In: Neotropical Social Wasps. Springer, Cham, chapter 3, p. 45-69.

DETONI, M.; BARBOSA, B. C.; MACIEL, T. T.; SANTOS, S. J. L.; PREZOTO, F. Long-and short-term changes in social wasp community structure in an urban area. Sociobiology, v. 65, n. 2, p. 305-311, 2018.

DOSSA, D.; DA SILVA, H. D.; BELlOTE, A. F. J.; RODIGHERI, H. R. Produção e rentabilidade dos eucaliptos em empresas florestais. Embrapa Florestas-Comunicado Técnico (INFOTECA-E), 2002.

ELISEI, T.; RIBEIRO JUNIOR, C.; FERNANDES JUNIOR, A. J.; NUNES, J. V.; DE SOUZA, A. R.; PREZOTO, F. Management of social wasp colonies in eucalyptus plantations (Hymenoptera: Vespidae). Sociobiology, v. 59, n. 4, p. 1167-1174, 2012.

FELIPPOTTI, G. T.; MATEUS, M.; MATEUS, S.; NOLL, F. B.; ZUCCHI, R. Morphological caste diferences in three species of the neotropical genus Clypearia (Hymenoptera: Polistinae: Epiponini). Psyche: 
A Journal of Entomology, v. 2010, 2010.

FREITAS, J. L.; PIRES, E. P.; OLIVEIRA, T. T. C.; SANTOS, N. L.; SOUZA, M. M. Vespas sociais (Hymenoptera: Vespidae) em lavouras de Coffea arabica L. (Rubiaceae) no Sul de Minas Gerais. Revista Agrogeoambiental, v. 7, n. 3, p. 67-77, 2015.

GIANNOTTI, E.; PREZOTO, F.; MACHADO, V.L.L. Foraging activity of Polistes lanio lanio (Fabr.) (Hymenoptera, Vespidae). In: Anais da Sociedade Entomológica do Brasil, v. 24, n. 3, p. 455-463, 1995.

GOMES, B.; NOLL, F. B. 2009. Diversity of social wasps (Hymenoptera, Vespidae, Polistinae) in three fragments of semideciduous seasonal forest in the northwest of São Paulo State, Brazil. Revista Brasileira de Entomologia, v. 53, n. 3, p. 428-431, 2009.

HENRIQUES, R. P. B.; DINIZ, I. R.; KITAYAMA, K. Nest density of some social wasp species in Cerrado vegetation of central Brazil (Hymenoptera: Vespidae). Entomol Gener, v. 17, p. 265-268, 1992.

LIMA, A. C. de O. Sobre a diversidade das vespas sociais (Vespidae: Polistinae) em fragmentos florestais remanescentes do noroeste e do nordeste do estado de São Paulo, e o seu possível uso como indicadores de conservação da biodiversidade. 2008. 66 f. Dissertação (Mestrado em Ciências - Entomologia) Faculdade de Filosofia, Ciências e Letras de Ribeirão Preto da USP, Ribeirão Preto, São Paulo, 2008.

MACIEL, T. T.; BARBOSA, B. C.; PREZOTO, F. Armadilhas Atrativas como Ferramenta de Amostragem de Vespas Sociais (Hymenoptera: Vespidae):Uma Meta-Análise. EntomoBrasilis, v. 9, n. 3, p. 150-157, 2016.

MALHEIROS, Roberto. A influência da sazonalidade na dinâmica da vida no bioma cerrado. Revista Brasileira de Climatologia, v. 19, 2016.

MELO, A. C.; BARBOSA, B. C.; CASTRO, M. M. de; SANTOS, G. M. de M.; PREZOTO, F. The social wasp community (Hymenoptera, Vespidae) and new distribution record of Polybia ruficeps in an area of Caatinga Biome, northeastern Brazil. Check List, v. 11, n. 1, 2015.

NEVES, F. S.; BRAGA, R. F.; ARAÚJO, L. S.; CAMPOS, R. I.; FAGUNDES, M. Differential effects of land use on ant and herbivore insect communities associated with Caryocar brasiliense (Caryocaraceae). Revista de Biologia Tropical, v. 60, n. 3, p. 1065-1073, 2012.

PEREIRA, K. M. G.; CABACINHA, C. D.; MATOS, L. M. A.; PLAZAS, I. C. V. Composição florística e fitossociológica do cerrado sensu stricto no Parque Estadual da Lapa Grande, Montes Claros, MG. Enciclopédia Biosfera, v. 13, n. 24, p. 290-305, 2016.

PILON, N. A. L.; UDULUTSCH, R. G.; DURIGAN, G. Padrões fenológicos de 111 espécies de Cerrado em condições de cultivo. Hoehnea, v. 42, n. 3, p. 425-443, 2015.

PIRANI, F. R.; SANCHEZ, M.; PEDRONI, F. Fenologia de uma comunidade arbórea em cerrado sentido restrito, Barra do Garças, MT, Brasil. Acta Botanica Brasilica, v. 23, n. 4, p. 1096-1110, 2009.

PREZOTO, F.; MACIEL, T. T.; DETONI, M.; MAYORQUIN, A. Z.; BARBOSA, B. C. Pest Control Potential 
of Social Wasps in Small Farms and Urban Gardens. Insects, v. 10, n. 7, p. 192, 2019.

PREZOTO, F. A importância das vespas como agentes no controle biológicos de pragas. Revista Biotecnologia, v. 2, n. 9, p. 24-26, 1999.

PREZOTO, F.; CORTES, S. A. O.; MELO, A. C. Vespas: de vilãs a parceiras. Ciência Hoje, v. 43, n. 253, p. 70-73, 2008.

RIBEIRO JÚNIOR, C. Levantamento de vespas sociais (Hymenoptera, Vespidae) em eucaliptocultura. 2008. 68 f. Dissertação (Mestrado em Biologia e Comportamento animal), Universidade Federal de Juiz de Fora, Instituto de Ciências Biológicas, Juiz de Fora, 2008.

SANTOS, G. M. M.; CRUZ, J. D. da; MARQUES, O. M.; GOBBI, N. Diversidade de Vespas Sociais (Hymenoptera: Vespidae) em Áreas de Cerrado na Bahia. Neotropical Entomology, v. 38, n. 3, p. 317-320, 2009.

SHANNON, C. E.; WEAVER, W. The mathematical theory of communication. Urbana: University Illionis Press, 1949.

SILVA, S. de S.; SILVEIRA, O. T. Vespas sociais (Hymenoptera, Vespidae, Polistinae) de floresta pluvial Amazônica de terra firme em Caxiuanã, Melgaço, Pará. Iheringia. Série Zoologia, v. 99, n. 3, p. 317-323, 2009.

SILVEIRA-NETTO, S.; NAKANO, O.; BARBIN, D.; NOVA, N. A.V. Manual de Ecologia dos Insetos. São Paulo, Editora Agronômica Ceres, 419p. 1976.

SIMÕES, M. H.; CUOZZO, M. D.; FRIEIRO-COSTA, F. A. Diversity of social wasps (Hymenoptera, Vespidae) in Cerrado biome of the southern of the state of Minas Gerais, Brazil. Iheringia. Série Zoologia, v. 102, n. 3, p. 292-297, 2012.

SOMAVILLA, A.; OLIVEIRA, M. L.; RAFAEL, J. A. Social Wasps (Vespidae: Polistinae) from Two National Parks of the Caatinga Biome, in Brazil. Sociobiology, v. 64, n. 3, p. 334-338, 2017.

SOMAVILLA, A.; OLIVEIRA, M. L. D.; SILVEIRA, O. T. Guia de identificação dos ninhos de vespas sociais (Hymenoptera, Vespidae, Polistinae) na Reserva Ducke, Manaus, Amazonas, Brasil. Revista Brasileira de Entomologia, v. 56, n. 4, p. 405-414, 2012.

SOUZA, C. A. S.; VALE, A. C. G.; BARBOSA, B. C. Checklist de Vespas Sociais (Vespidae: Polistinae) em Duas Áreas Verdes Urbanas no Município de Barra Mansa, Rio de Janeiro, Brasil. EntomoBrasilis, v. 9, n. 3, p. 169-174, 2016.

SOUZA, M. M.; LADEIRA, T. E.; ASSIS, N. R. G.; CAMPOS, A. E.; CARVALHO, P.; LOUZADA, J. N. C. Ecologia de vespas sociais (Hymenoptera, Vespidae) no Campo Rupestre na Área de Proteção Ambiental, APA, São José, Tiradentes, MG. MG-Biota, v. 3, p. 15-32, 2010.

TOGNI, O. C. Diversidade de vespas sociais (Hymenoptera, Vespidae) na Mata Atlântica do litoral norte do estado de São Paulo. 2009. 99 f. Dissertação (Mestrado em Ciências Biológicas - Zoologia) - 
Universidade Estadual Paulista Júlio Mesquita Filho, Rio Claro, São Paulo, Brasil, 2009.

VIRGÍNIO, F.; MACIEL, T. T.; BARBOSA, B. C. Novas contribuições para o conhecimento de vespas sociais (Hymenoptera: Vespidae) para Estado do Rio Grande do Norte, Brasil. Entomotropica, v. 31, n. 26, p. 221-226, 2016. 